\title{
Análise envoltória de dados na eficiência inovativa de propriedades leiteiras
}

\section{Data envelopment analysis on innovative efficiency of dairy farms}

Versão do autor aceita publicada online: 26 abr. 2021

Publicado online: 30 jun. 2021

Como citar esse artigo - American Psychological Association (APA): Brianez, G. P., \& Sabbag, O. J. (2021). Análise envoltória de dados na eficiência inovativa de propriedades leiteiras. Exacta. DOI: https://doi.org/10.5585/exactaep.2021.18429.

\section{Guilherme Pelegrini Brianez}

https://orcid.org/0000-0003-4617-8210

Faculdade de Ciências Agrárias e Veterinárias - FCAV - Unesp - Jaboticabal

Mestrando em Administração pela Faculdade de Ciências Agrárias e Veterinárias - FCAV. Pósgraduado em Gestão de Pequenos Negócios pela Fundação Getúlio Vargas (2016) e em Gerenciamento de Projetos pelo Centro Universitário Barão de Mauá (2015). Possui graduação em Administração de Empresas pelo Centro Universitário da Fundação Educacional de Barretos (2004). Tem experiência na área de Administração, com ênfase em Administração de Empresas. Atualmente é Consultor de Negócios do SEBRAE-SP, suas atividades consistem em orientações individuais e coletivas em temas de Gestão Empresarial para pequenos negócios nos segmentos de agronegócio, comércio, indústria e serviços.

\section{Omar Jorge Sabbag}

https://orcid.org/0000-0003-3940-4240

UNESP/FEIS, Ilha Solteira (SP).

Possui graduação em Agronomia pela Universidade Estadual Paulista Júlio de Mesquita Filho UNESP/FEIS (2000), mestrado em Agronomia (sistemas produtivos e gestão) pela UNESP/FEIS (2002), doutorado em Geografia (planejamento ambiental e gestão) pela UNESP/FCT (2006) e pósdoutorado em Zootecnia (políticas públicas e desenvolvimento) pela UNESP/FEIS (2012). Atualmente é professor associado da UNESP/FEIS e docente orientador nos programas de pós-graduação em Desenvolvimento Regional e de Sistemas Produtivos (UEMS) e Mestrado Profissional em Administração (FCAV/UNESP). Tem experiência em Economia e Gestão do Agronegócio, com atuação em: análise de investimentos e riscos, análise de eficiência, empreendedorismo rural e gestão, políticas públicas para o agronegócio, desenvolvimento regional e sustentabilidade.

\section{Resumo}

A pecuária leiteira é importante atividade do agronegócio brasileiro que apresenta desafios devido à heterogeneidade no perfil das propriedades, alto custo operacional e baixo retorno financeiro para a maioria dos pequenos produtores. O presente trabalho tem por objetivo avaliar a efíciência técnica de 12 propriedades leiteiras em regiões do estado de São Paulo, por meio da Análise Envoltória de Dados (DEA). Verificou-se relação de inovação tecnológica e não tecnológica nos índices de produção leiteira. As variáveis do estudo foram a produtividade diária de leite, área (hectares), número de animais lactantes e mão de obra. Assim, 33\% das propriedades foram consideradas eficientes e $67 \%$, ineficientes. Conclui-se que a capacitação técnica é diferencial, bem como o estímulo ao desenvolvimento tecnológico, não tecnológico e 
gerencial de forma individual e coletiva. Entidades públicas e privadas também são importantes para o avanço e para promover maior sustentabilidade aos produtores de leite.

Palavras-chave: Cadeia leiteira. Capacitação técnica. Desempenho. DEA. Inovação. Produção de leite.

\begin{abstract}
Dairy farming is an important activity of Brazilian agribusiness that presents challenges due to the heterogeneity in the profile of properties, high operational cost and low financial return for smallest producers. The present paper aimed to evaluate the technical efficiency of 12 dairy farms in regions of the state of São Paulo, through Data Envelopment Analysis (DEA). The relation of technological and non-technological innovation in the dairy production indexes was verified. The study variables were the daily milk productivity in liters, the area used in hectares, the number of lactating animals and labor. Like this, 33\% of the properties were considered efficient and $67 \%$, inefficient. It is concluded that technical training is differential, as well as encouraging technological, non-technological and managerial development individually and collectively. Public and private entities are also important for the advancement and to promote greater sustainability for milk producers.
\end{abstract}

Keywords: Dairy chain. Technical capacitation. Performance. DEA. Innovation. Milk Production.

\title{
1 Introdução
}

O agronegócio destaca-se no Brasil por promover o desenvolvimento da economia por meio da geração de emprego e manutenção da balança comercial positiva, devido aos índices substanciais de exportações que mantêm o PIB brasileiro. Recursos naturais, tecnologia e conhecimento fazem com que o país seja um dos principais produtores e exportadores de produtos do campo (Wilkinson, 2015).

O Brasil ocupa posição de destaque na produção de alimentos perante o mundo e de acordo com a Associação Brasileira da Indústria dos Alimentos (ABIA, 2019), no ano de 2018 o setor brasileiro de alimentos, registrou crescimento de $2,08 \%$ e receita de $\mathrm{R} \$ 656$ bilhões. E, dentro deste contexto, insere-se a pecuária leiteira, uma das mais importantes atividades do agronegócio brasileiro.

Nosso país encontra-se entre os principais produtores de leite mundiais, e de acordo com a FAO (2016), aproximadamente 150 milhões de famílias atuam na produção leiteira. No ano de 2017, o país produziu 8,9 bilhões de litros de leite, envolvendo 1,1 milhão de propriedades rurais, sendo o quinto maior produtor de leite no mundo (Embrapa, 2018). 
A produção de leite ocorre em escala mundial, sendo essencial para diversas economias, em especial, nos países de economia emergente. Nos últimos trinta anos, o setor de produção leiteira apresentou crescimento acima de 50\%, alcançando 769.106 t em 2013 (FAO, 2016). Na cadeia leiteira, o principal agente é o produtor rural, que operacionaliza de forma integrada com a indústria, no que se refere aos insumos adquiridos e ao fornecimento da matéria-prima para industrialização e comercialização. Toda a alocação de mão de obra e recursos advém da estrutura familiar e contribui para a diminuição do êxodo rural (Eurich et al., 2016).

Souza Almeida, Gomes e Freitas (2021) avaliaram 31 produtores de leite e observaram que agricultores ineficientes buscaram as melhores práticas e a escala de produção ideal baseando-se na avaliação de eficiência, correspondente às variáveis de análise do presente estudo.

Considerando que a análise da eficiência técnica e do perfil inovativo das propriedades leiteiras do interior do estado de São Paulo pode contribuir com o estímulo para o aperfeiçoamento e a criação de estratégias competitivas e de desenvolvimento tecnológico de propriedades menos produtivas, o objetivo do presente estudo foi avaliar a eficiência inovativa de 12 produtores de leite do estado de São Paulo por meio da análise envoltória de dados em ações de gestão, acesso ao mercado e inovações tecnológicas e não tecnológicas.

\section{Referencial Teórico}

\subsection{Produção de leite brasileira e análise DEA}

Na década de 1990, a atividade leiteira passou por intenso desenvolvimento tecnológico e com o livre mercado, de modo que produtos lácteos de outros países invadiram o Brasil. Com isso, o mercado interno foi prejudicado, mas a cadeia leiteira brasileira se reinventou introduzindo tecnologías e processos para aumentar sua participação no mercado (Dias, 2012).

O Brasil, em 2018, estava entre os dez países mais produtivos do mundo, com 33,8.10 L de leite, e avançou 1,6\% em relação à 2017 (IBGE, 2019), sendo o estado de São Paulo responsável por $1,64.10^{9} \mathrm{~L}$.

O resultado apresentado pelo Brasil é considerado baixo, comparado aos EUA e Alemanha que produziram 10.457 L/animal e 7.780 L/animal de leite no ano de 2017 respectivamente (EMBRAPA, 2019). Ambos os países ocupam as primeiras posições em produção e produtividade por animal no mundo. 
De acordo com a EMBRAPA (2019), nos anos de 2016 e 2017, o Brasil ocupou a $3^{\text {a }}$ posição em produção e produtividade de leite no mundo. O Brasil registrou pequena retração de $0,5 \%$ na produção de leite em 2017, comparado ao ano de 2016, mas apresentou aumento de quase $15 \%$ na produtividade por animal em relação ao período anterior. Os resultados indicam o potencial avanço da eficiência produtiva do rebanho, bem como a inserção de novos produtores na atividade.

A produção leiteira é caracterizada pelos sistemas de produção intensivo, extensivo e misto, de modo que a opção pela utilização de um sistema, depende de algumas variáveis, tais como disponibilidade de recursos financeiros, conhecimento, mão de obra, etc. Em paísés desenvolvidos, o sistema intensivo é mais comum; em contrapartida, nos países em desenvolvimento o método extensivo é mais utilizado (Eurich et al., 2016).

De acordo com a Embrapa (2018), no Brasil, 90\% dos produtores de leite adotam o sistema extensivo, com produção de até 1.200 L/animal ano, o que corresponde à 33\% da produção nacional.

A modernização na pecuária de leite demanda especialização de recursos humanos, como alternativa para sua continuidade (Brandão, 2001). Além disso, a inovação em processos e organização na cadeia leiteira, tem ocorrido para a melhoria da competitividade (Corrêa, Veloso \& Barczsz, 2010). Para isto, quanto maior a escolaridade dos produtores rurais, maior o potencial para adoção de inovação tecnológica (Dantas et al., 2016).

Cardenas, Pacheco e Dias (2018) analisaram por meio de entrevistas, as inovações de produto, processo, posição e paradigma na cadeia bovina brasileira nas últimas duas décadas e observaram que, apesar do progresso na melhoria da qualidade do produto e obtenção de ganhos de eficiência produtiva, a qualidade ainda é desafio no setor. Entretanto, segundo Ferenhof et al. (2019), melhorias na qualidade e produtividade poderiam ser realizadas por meio da interação entre centros de pesquisa, cooperativas, agências financeiras, produtores rurais, transportadores e outros agentes, promovendo intercâmbio de conhecimentos e processos.

A Embrapa Pecuária Sudeste desenvolveu o Projeto Balde Cheio, que se consolidou na transferência de tecnologia e capacitação aos produtores. Similar a esse programa, o Educampo, que é uma parceria entre a Universidade Federal de Viçosa e o SEBRAE de Minas Gerais, fornece assistência técnica e gerencial para produtores de leite (Nascimento et al., 2012).

A inovação nas empresas afeta o desenvolvimento e a aplicação de tecnologias e a reorganização de processos de negócios, relações externas e marketing. A literatura enfatiza a importância de integrar produto, processo e organização para transformar ideias em sucesso de 
mercado. Neste sentido, na indústria agroalimentar, o conceito de inovação foi estendido a inovações tecnológicas e não tecnológicas (Caiazza, Volpe \& Stanton, 2016).

De acordo com Schreiber (2002), há exemplos como do Quênia, em que laticínios incentivam investimento em novas tecnologias e oferecem aos produtores a oportunidade de aumentar a renda. No México, Córtez-Arriola et al. (2015) observaram que as características gerenciais e empreendedores precisavam ser consideradas ao projetar inovações na propriedade leiteira.

Após análise do perfil de 170 produtores de leite da região central do México, GarcíaVillegas et al. (2020) observaram que os jovens com maior nível escolar utilizam tecnologias emergentes para comunicar informações relacionadas ao manejo da pecuária com outros agricultores. Klerkx e Begemann (2020) destacaram que uma abordagem de sistemas de inovação agrícola pode auxiliar a compreender como a inovação, em diferentes escalas geográficas, se desenvolve para permitir a transformação dos sistemas alimentares. Os pontos de interesse podem estar na compreensão dos impulsionadores, redes e governança.

A eficiência é a relação entre produção e potencial de produção com base nos recursos disponibilizados. A eficiência refere-se às atividades “meio", ou seja, à execução para obtenção de resultado. Eficácia refere-se aos resultados finalísticos alcançados e ou pretendidos dentro de uma ação ou projeto (Pachiel, 2009).

A Análise Envoltória de Dados (Data Envelopment Analysis - DEA), baseia-se em programação matemática não paramétrica e avalia a eficiência de unidades produtivas, conhecidas por DMU (Decision Making Units), na presença e ou relação de inputs e outputs. A DEA tem sido utilizada com mais frequência nos últimos anos em virtude de sua flexibilidade e versatilidade em relação aos dados utilizados para análise, pois aplica-se em diversos setores e segmentos com variáveis múltiplas (Mello et al., 2005).

De acordo com Farrell (1957) e Pereira (2014), há três tipos de eficiência relativa: técnica, alocativa e econômica. Para a eficiência técnica, deve ocorrer o máximo de produção (output/saídas) para certo conjunto de insumos (input/entradas) com foco para output/saídas; ou o mínimo de insumos (input/entradas) para dado output/saídas com o objetivo de input/entradas.

Além do modelo denominado CRS - Constant Returns to Scale, que publicou seu primeiro artigo em 1978, pela European Journal of Operations Research, em 1984 foi criado o modelo VRS - Variable Returns to Scale, desenvolvido por Banker, Charnes e Cooper - BCC, que é empregado para determinar a eficiência técnica e de escala e permite identificar ganhos de escala constantes, crescentes e decrescentes (Kassai, 2002). 
Para os modelos CRS e VRS, podem ser utilizadas as orientações para insumos e ou produtos. Conforme Kassai (2002) e Charnes et al. (1997), o modelo linear CRS empregado na forma ganhos de escala constantes, na orientação insumos é denominado CCR - Insumo; na orientação produtos é denominado CCR - Produto. No modelo linear BCC, com ganhos de escala variáveis, na orientação insumos, denomina-se BCC - Insumo; na orientação produtos é BCC - Produto.

A comparação entre as unidades eficientes e não eficientes caracteriza-se uma das principais vantagens da técnica DEA. É fundamental que as variáveis escolhidas para a análise da eficiência sejam orientadoras no processo decisório da liderança (Arzubi \& Berbel, 2002).

De acordo com Canziani (2003), os fatores mais importantes para o aumento da eficiência no processo de produção, são a sanidade, a alimentação e a alta genética que fornecem subsídios para a manutenção da qualidade na produção de leite.

Buss et al. (2020) analisaram a eficiência em 15 propriedades leiteiras de acordo com mão de obra, área, vacas em lactação, investimento e produção de leite em L/mês. As propriedades eficientes produziam acima de $100 \mathrm{~L} / \mathrm{dia}$, implementaram melhoramento genético, disponibilizaram mais alimentos aos animais, recebiam periodicamente assistência técnica e capacitação.

Um dos principais objetivos da DEA é identificar pontos de melhoria para estruturação de um plano de ação assertivo. Desta forma, de acordo com Lima et al. (2016), utilizando a mesma técnica, em um estudo com 150 assentados, a eficiência média foi de 62,8\%. Entretanto, em relação aos assentados considerados de baixo desempenho, foram propostas ações como programas de extensão, cursos de capacitação técnica, preparação para o escoamento da produção, controle de pragas e doenças, plantio de árvores, rotação de cultura e práticas de combate à erosão, de modo a ajudá-los para atingir a eficiência.

\section{Metodologia}

Foram analisadas 12 DMU's produtoras de leite com área de até 60 ha, de forma individual, no período de julho a novembro de 2019. As DMU's situam-se nos municípios de Barretos, Bebedouro, Cajobi, Colina, Guaíra, Ipuã, Sabino, São José do Rio Preto e Viradouro. Os produtores participantes do estudo receberam de forma direta ou indireta atendimentos do Serviço Brasileiro de Apoio à Micro e Pequena Empresa - SEBRAE.

A pesquisa desenvolvida foi exploratória descritiva com as abordagens a quantitativa e qualitativa, divididas em duas etapas. A primeira etapa consistiu na abordagem quantitativa 
utilizando a análise de eficiência, por meio da análise com a orientação input - CRS (Constant Returns to Scale), com quatro variáveis inputs (área em ha, número de animais lactantes e número de mão de obra) e uma output (produção total de L/dia). Para a utilização da DEA, de acordo com Ali e Seiford (1993), o espaço amostral avaliado deve compreender a relação mínima de $2(\mathrm{X}+\mathrm{Y})$, sendo X-inputs e y-outputs. Sabbag (2017), reforça a importância de homogeneidade dos pacotes tecnológicos avaliados.

Para a apuração das variáveis investigadas e obtidas junto aos produtores de leite, foi utilizado o software DEAP 2.1 (Data Envelopment Analysis Program) exposto por Coelli (1996). Após as informações geradas no sistema, os resultados de cada unidade foram representados e discutidos no presente estudo.

Destaca-se que as formulações matemáticas propostas para este estudo, referente ao modelo DEA e respectiva orientação deste método não paramétrico foram baseadas em Azambuja (2002).

A segunda etapa fundamentou-se no método qualitativo e teve por objetivo identificar, nos últimos três anos, junto às DMU's mais eficientes, a relação com ações de inovações tecnológicas e não tecnológicas.

As variáveis do estudo referem-se às DMU's e foram obtidas internamente, decorrente de um cadastro prévio dos produtores. A definição das variáveis, e seu respectivo tratamento, foi dividida em duas etapas para melhor organização, sendo:

$1^{\text {a }}$ etapa: refere-se à análise de eficiência por meio da DEA com a abordagem quantitativa. As variáveis foram: área em ha (Input), número de animais lactantes (Input), número de mão de obra (Input) e produção total de L/dia (Output).

$2^{\text {a }}$ etapa: análise de inovações tecnológicas e não tecnológicas implantadas nos últimos 3 anos, por meio de abordagem qualitativa, junto às DMU's mais eficientes. As variáveis foram condicionadas a algumas características, dentre as quais perfil profissional, composto de nome completo, telefone celular, município, idade, grau de escolaridade e há quanto tempo atua na atividade leiteira (em anos); perfil da propriedade e ações nos 3 eixos: gestão, acesso ao mercado e tecnologia/inovação.

Os critérios utilizados para a seleção da amostra foram os seguintes:

- 12 DMU's produtoras de leite situadas no estado de São Paulo. Os produtores de leite participantes foram de Barretos, Bebedouro, Cajobi, Colina, Guaíra, Ipuã, Sabino, São José do Rio Preto e Viradouro, localizados nas regiões da Alta Mogiana, Centro Norte e Centro Oeste. 
- DMU's com até 4 módulos fiscais de acordo com cada município em conformidade com o estabelecido pelo IBGE.

- DMU's com até 200 animais lactantes produzindo leite diariamente.

Os produtores de leite envolvidos no estudo foram informados sobre os objetivos da pesquisa, bem como de sua confidencialidade e preservação das identidades.

Para a coleta de dados, foram utilizadas pesquisa bibliográfica e entrevista composta por perguntas que foram desenvolvidas e adaptadas com base em questionários utilizados pela Agência Paulista de Tecnologia dos Agronegócios-APTA - Unidade Alta Mogiana, situada em Colina (SP), e também pela Coordenadoria de Desenvolvimento Rural Sustentável-CDRS, ambas as instituições atuam com pesquisa, extensão e apoio técnico e são órgãos pertencentes à Secretaria de Agricultura do Estado de São Paulo.

O questionário foi desenvolvido por meio do formulário Google Forms e disponibilizado com as instruções por meio de link de aplicativo de mensagens e e-mail aos produtores de leite participantes do estudo. Foi disponibilizado aos participantes da pesquisa o Termo de Consentimento Livre e Esclarecido.

Para a identificação de ações inovadoras nos últimos três anos junto às DMU's mais eficientes, foi analisada a implantação de produtos ou serviços, processos, método de marketing e organizacional novo ou significativamente melhorado (Manual de Oslo, 2018), visando ao aumento da produtividade.

\section{Resultados e Discussão}

Inicialmente, a eficiência média obtida pelos produtores de leite foi de $72,1 \%$. O resultado reforça a tendência para baixa eficiência operacional na produção leiteira brasileira. Assim, 33\% das DMU's possuem 100\% de eficiência, o que significa a otimização de recursos envolvidos no sistema de produção utilizado. As DMU's 1, 2, 3 e 9 apontaram com máxima eficiência, destacando-se algumas considerações importantes, dentre as quais:

a) 10 DMU's são gerenciadas por homens $(83 \%)$ e 2 por mulheres $(17 \%)$;

b) A idade é representada da seguinte forma: até 30 anos (1 propriedade); de 30 a 50 anos (5 propriedades) e acima de 50 anos (6 propriedades), atestando que 50\% das DMU's são gerenciadas por produtores de leite com mais experiência na atividade;

c) O nível de escolaridade dos produtores de leite são: ensino fundamental (1 produtor); ensino médio (5 produtores); graduação (3 produtores) e pós-graduação (3 produtores); 
d) O tempo de atuação na atividade leiteira dos produtores são: até 10 anos (4); de 10 a 20 anos (2); de 20 a 30 anos (4) e acima de 30 anos (2).

A tabela 1 mostra as variáveis analisadas do estudo por DMU: área em ha (Input); número de animais lactantes produzindo (Input); número de funcionários envolvidos na atividade (Input); e produção média de L/dia (Output). Em relação às 12 DMU's avaliadas, a produção média de leite é de 38,66 L/dia ha.

A tabela 2 que mostra as DMU's 2 e 9 possuem melhor produção média diária, acompanhadas pelas DMU's 1 e 6. Além disso, as DMU's 1, 2 e 9 estiveram entre as quatro DMU's com 100\% de eficiência em relação ao grupo pesquisado (escore 1). As DMU's 7 e 8 apresentaram baixa produção e ratificam como propriedades com maior necessidade de desenvolvimento e melhoria neste quesito.

A DMU 3, que apresenta produção média de 12,73 L/animal dia, encontra-se no grupo das propriedades consideradas mais eficientes, e seu sistema de produção é de pasto e semiconfinamento. As DMU's 1, 2 e 9 apresentam 50\% mais produção em litros de leite por animal do que a propriedade 3 .

Tabela 1: Variáveis individuais utilizadas na análise de eficiência por meio da DEA

\begin{tabular}{ccccc}
\hline DMU & $\begin{array}{c}\text { Área em ha } \\
(\mathbf{I})\end{array}$ & $\begin{array}{c}\text { Número de } \\
\text { animais } \\
\text { lactantes }(\mathbf{I})\end{array}$ & $\begin{array}{c}\text { Número de } \\
\text { funcionários } \\
(\mathbf{I})\end{array}$ & Produção L/dia (O) \\
\hline 1 & 8 & 34 & 2 & 650 \\
2 & 2,42 & 100 & 10 & 2.000 \\
3 & 50 & 110 & 4 & 1.400 \\
4 & 9,5 & 29 & 2 & 480 \\
5 & 14 & 9 & 1 & 85 \\
6 & 6 & 30 & 3 & 540 \\
7 & 3 & 45 & 5 & 400 \\
8 & 8 & 5 & 1 & 30 \\
9 & 60 & 50 & 5 & 1.000 \\
10 & 4,8 & 11 & 2 & 125 \\
11 & 3 & 23 & 3 & 260 \\
12 & 18 & 23 & 2 & 250 \\
\hline Total & $\mathbf{1 8 6 , 7 2}$ & $\mathbf{4 6 9}$ & $\mathbf{4 0}$ & $\mathbf{7 . 2 2 0}$ \\
\hline
\end{tabular}

Fonte: Elaborado pelo autor. 
Tabela 2: Produção média de L/dia por animal lactante nas 12 DMU's

\begin{tabular}{cccc}
\hline DMU & $\begin{array}{c}\text { Número de } \\
\text { animais } \\
\text { lactantes }\end{array}$ & $\begin{array}{c}\text { Produção } \\
\text { de L/dia }\end{array}$ & Produção média de L/dia animal \\
\hline 1 & 34 & 650 & 19,12 \\
2 & 100 & 2000 & 20,00 \\
3 & 110 & 1.400 & 12,73 \\
4 & 29 & 480 & 16,55 \\
5 & 9 & 85 & 9,44 \\
6 & 30 & 540 & 18,00 \\
7 & 45 & 400 & 8,89 \\
8 & 5 & 30 & 6,00 \\
9 & 50 & 1.000 & 20,00 \\
10 & 11 & 125 & 11,36 \\
11 & 23 & 260 & 11,30 \\
12 & 23 & 250 & 10,87 \\
\hline Total & $\mathbf{4 6 9}$ & $\mathbf{7 . 2 2 0}$ & $\mathbf{1 3 , 6 9}$ \\
\hline
\end{tabular}

Fonte: Elaborado pelo autor

A Tabela 3 apresenta a estatística descritiva das variáveis do estudo realizado em doze propriedades leiteiras do Estado de São Paulo de julho a novembro de 2019, principalmente os valores mínimos e máximos. A DMU com menor área possui 2,42 ha e a maior 60 ha, a média em ha do espaço amostral é de 15,56 ha. Para as vacas lactantes, a DMU com menor número possui 5 e a maior com 110 cabeças, perfazendo média de 39 animais/propriedade. A DMU com menor número de funcionários corresponde a 1 pessoa e a maior possui 10 envolvidos, inferindo-se que quanto maior o número de trabalhadores, mais elevadas são as ações, serviços e produtividade. A produção de leite diária menor é de $30 \mathrm{~L}$, e a maior de $2.000 \mathrm{~L}$, com média de $60 \mathrm{~L} /$ dia espaço amostral.

Tabela 3: Estatística descritiva das variáveis em doze propriedades leiteiras

\begin{tabular}{lccccc}
\hline \multicolumn{1}{c}{ Variáveis } & Unidade & Total & Média & Mínimo & Máximo \\
\hline Área (I) & ha & 186,72 & 15,56 & 2,42 & 60 \\
Animais lactantes (I) & Cabeça & 469 & 39,08 & 5 & 110 \\
Mão de obra (I) & Número & 40 & 3,33 & 1 & 10 \\
Produção de leite diária (O) & $\mathrm{L}$ & 7.220 & 601,67 & 30 & 2.000 \\
\hline
\end{tabular}

Fonte: Elaborado pelo autor. I: Input; O: Output.

A figura 1 mostra a distribuição da eficiência técnica no modelo DEA, em que as DMU's 1, 2, 3 e 9 foram consideradas pares de excelência e respondem por 64,49\% das áreas em ha, $62,68 \%$ dos animais lactantes, $52,50 \%$ da mão de obra (funcionários) e 69,94\% da produção 
média diária de leite. Itens como a escolaridade elevada e tempo na atividade apontam positivamente para os resultados. Em relação à escolaridade, em parte difere do estudo de Nascimento et al. (2012), que relata a escolaridade associada à maior área utilizada por animal como fator não determinante da eficiência das propriedades. As DMU's mais eficientes são utilizadas como benchmarking para as propriedades com necessidades de melhoria.

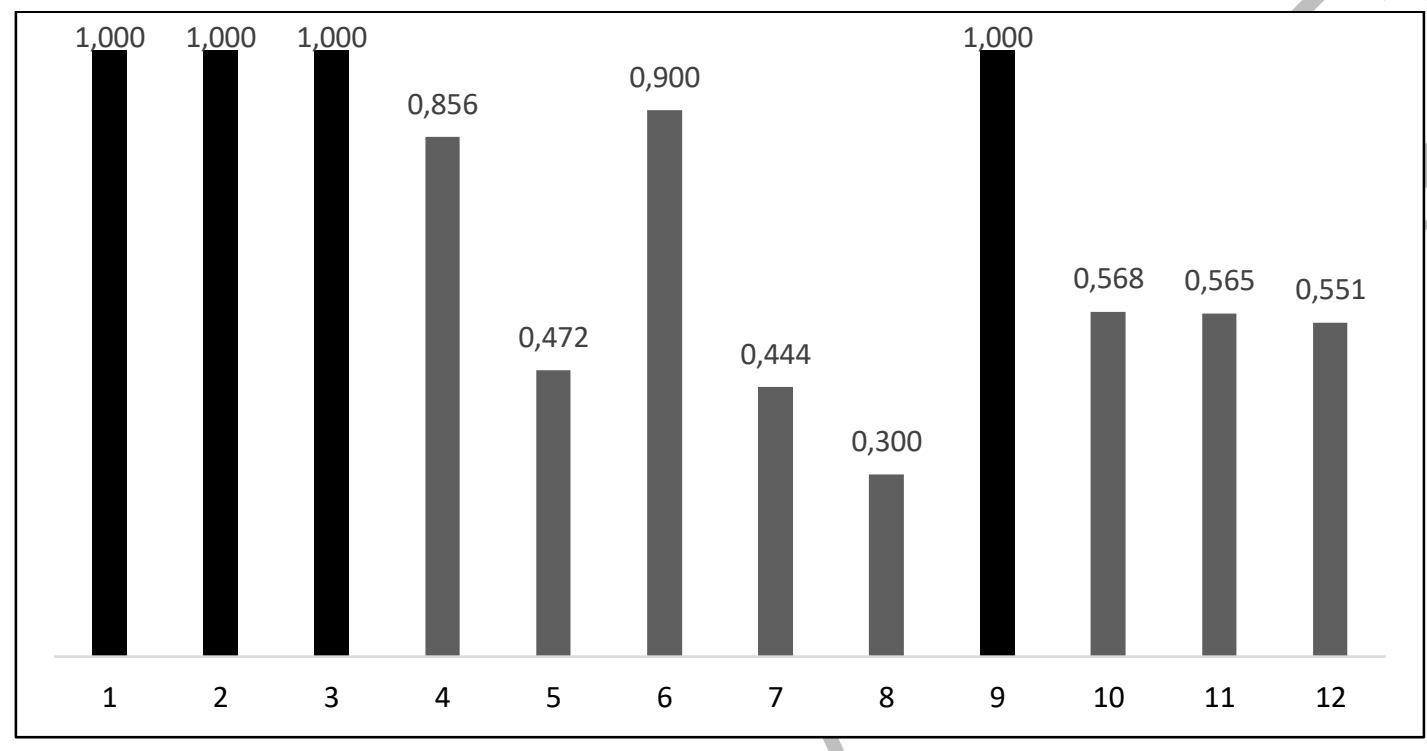

Figura 1: Distribuição da eficiência técnica no modelo DEA - CCR (input). Fonte: Elaborado pelo autor.

As unidades referenciais representam $33 \%$ e o resultado é próximo do encontrado por Stockes (2007), em seu estudo na Pensilvânia, mostrou que $29 \%$ de propriedades produtoras de leite são eficientes. Os produtores de leite com melhores níveis de eficiência incorporam mais recursos, ações e tecnologia no sistema de produção (Batalha, 2012).

A produção de leite demonstrada nas propriedades eficientes foi acima de $19 \mathrm{~L}$ corroborando com Barbieri (2016) em relação à produtividade mínima por sistemas de produção, sendo a produção de leite das propriedades consideradas eficientes, comercializada diretamente com a indústria de transformação. Enquanto Miranda e Graciosa (2018) consideraram 17,7 L de leite por animal por dia na média de propriedades eficientes, e 9,7 L para as menos produtivas, de acordo com o espaço amostral analisado pelos referidos autores.

A Tabela 4 mostra a distribuição por classe de eficiência. Foram utilizados 5 níveis para a classificação de acordo com os resultados apresentados. As 4 DMU's mais eficientes $(0,91$ 1,00) possuem maior representatividade em área $(67,70$ ha), número de animais $(69,08 \%)$, número de mão de obra $(60 \%)$ e produção de L/dia $(77,42 \%)$. 
Tabela 4: Distribuição por classe de eficiência entre as DMU's

\begin{tabular}{ccccccc}
\hline $\begin{array}{c}\text { Classe de } \\
\text { eficiência }\end{array}$ & $\begin{array}{c}\text { Número } \\
\text { de } \\
\text { DMU's }\end{array}$ & $\begin{array}{c}\text { \% } \\
\text { DMU's }\end{array}$ & Área (ha) & $\begin{array}{c}\text { Número } \\
\text { de } \\
\text { animais } \\
\text { lactantes }\end{array}$ & $\begin{array}{c}\text { Número } \\
\text { de } \\
\text { funcionário }\end{array}$ & $\begin{array}{c}\text { Produção } \\
\text { L/dia }\end{array}$ \\
\hline $0,01-0,40$ & 1 & 8,33 & 8 & 5 & 1 & 30 \\
$0,41-0,60$ & 5 & 41,67 & 42,8 & 111 & 13 & 1.120 \\
$0,61-0,80$ & 0 & 0,00 & 0 & 0 & 0 & 0 \\
$0,81-0,90$ & 2 & 16,67 & 9,5 & 29 & 2 & 480 \\
$0,91-1,00$ & 4 & 33,33 & 126,42 & 324 & 24 & 5.590 \\
\hline Total & $\mathbf{1 2}$ & $\mathbf{1 0 0 , 0 0}$ & $\mathbf{1 8 6 , 7 2}$ & $\mathbf{4 6 9}$ & $\mathbf{4 0}$ & $\mathbf{7 . 2 2 0}$ \\
\hline
\end{tabular}

Fonte: Elaborado pelo autor.

De forma geral, 75\% das DMU's, por meio de seus responsáveis, possuem graduação ou pós-graduação e se consideram inovadores. Ainda assim, uma das propriedades mais eficientes possui parceria e atua em diversos projetos com universidades e centros de pesquisa. De acordo com Ferenhof et al. (2019), a interação entre o ensino, pesquisa e extensão com a empresa rural deve ocorrer para promover maior qualidade e produtividade.

Sequencialmente, encontram-se na Tabela 5 as 2 DMU's com menor índice de eficiência em relação ao espaço amostral. As propriedades com esses resultados são as unidades 7 e 8 , sobretudo esta última que necessita de um ajuste de $70 \%$ entre as variáveis para tornar eficiente.

Tabela 5: DMU's menos eficientes da amostra

\begin{tabular}{cccccccc}
\hline DMU & $\begin{array}{c}\text { Eficiência } \\
\text { técnica }\end{array}$ & $\begin{array}{c}\text { Área } \\
\text { em ha } \\
\text { (I) }\end{array}$ & $\begin{array}{c}\text { Número } \\
\text { de } \\
\text { animais } \\
\text { lactantes } \\
\text { (I) }\end{array}$ & $\begin{array}{c}\text { Número de } \\
\text { funcionários } \\
\text { (I) }\end{array}$ & $\begin{array}{c}\text { Alvo } \\
\text { em } \\
\text { área } \\
\text { (há) }\end{array}$ & $\begin{array}{c}\text { Alvo em } \\
\mathbf{n}^{\mathbf{0}} \text { de } \\
\text { animais } \\
\text { lactantes }\end{array}$ & $\begin{array}{c}\text { Alvo em } \\
\text { número de } \\
\text { funcionários }\end{array}$ \\
\hline 7 & 0,444 & 3 & 45 & 5 & 0,849 & - & 0,222 \\
8 & 0,300 & 8 & 5 & 1 & 2,364 & - & 0,150 \\
\hline
\end{tabular}

Fonte: Elaborado pelo autor.

A produção média por animal das propriedades é abaixo de $10 \mathrm{~L} /$ dia, uma vez que 9 DMU's (75\% da amostra), apresentam produção acima de 10 L. Uma das DMU's consideradas menos eficientes possui animais da raça Jersey, atua com ordenha mecanizada, executa 2 ordenhas diárias e a produção é destinada em partes para a indústria e para a venda direta com agregação de valor: fabricação e venda de queijo. A outra DMU tem animais da raça Girolando, realiza uma ordenha manual diária no período matutino e toda a produção é destinada para a 
venda direta com agregação de valor para fabricação e venda de queijo. O sistema de produção em ambas é a pasto e praticam a rotação nas pastagens.

Apenas uma das DMU's faz adubação e irrigação total, a outra parcialmente. O tratamento de resíduos e análise da água para dessedentação do rebanho é feito em apenas uma propriedade. A análise de solo é praticada periodicamente em ambas. O cumprimento das Instruções Normativas (IN's) 77 e 78, de 2018, do Ministério da Agricultura, Pecuária e Abastecimento é realizado apenas por uma propriedade. O grau de escolaridade de ambos é ensino médio e periodicamente participam de capacitações como também são participativos em associação e/ou cooperativa.

A inseminação artificial é realizada visando a melhoria genética do plantel em apenas uma unidade. Os animais não são separados por homogeneidade nas DMU's. Os registros de informações climáticas, zootécnicas e financeiras são feitos manualmente. Na DMU 7 utiliza em média a mão de obra de 1 pessoa para o cuidado de 9 animais lactantes; já na DMU 8, usase 1 pessoa para 5 animais lactantes.

Em ambos os casos, há utilização em excesso dos insumos, tanto na área em ha como também no número de funcionários. Para a DMU 7, torna-se necessário a redução dos insumos (input) em 28,3\% (alvo 0,849) no item área; enquanto que para a mão de obra (input) deve-se reduzir 4,44\% (alvo 0,222). Da mesma forma, para a DMU 8 a diminuição de insumos (input) na área é de 29,55\% (alvo 2,364), e na mão-de-obra 15\% (alvo 0,150). A DMU 8 responde pela menor produção de litros de leite por dia dentro do espaço amostral, compreendendo $30 \mathrm{~L} / \mathrm{dia}$.

Ainda assim, 66\% das DMU's possuem até 10 ha de área. As raças dos animais lactantes são Gir, Holandesa, Jersey e mestiço. Os animais do espaço amostral possuem idade entre 2 e 6 anos. Apenas 2 DMU's executam ordenha manual, as outras 10 atuam de forma mecanizada/automatizada. Os animais são ordenhados 2 vezes ao dia em 11 DMU's, e 1 vez ao dia em 1 DMU. Todas as DMU's possuem tanque para resfriamento, mas apenas 11 utilizam.

Dentro do questionário desenvolvido e aplicado foi realizada uma pergunta ao produtor de leite, para saber, na visão dele, se ele se considera inovador ou possui inclinação para ações inovadoras. Destes, 8 (66\%) responderam que sim, e 4 (34\%) responderam que parcialmente. Em relação aos dados qualitativos, abaixo seguem os resultados mais relevantes para a discussão e conhecimento.

Na Tabela 6 foram divididos o questionário em 4 itens: genética, nutrição, sanidade e gestão, manejo e operação, para que fossem apresentados os percentuais em cada investigado nas 12 DMU's. 
Tabela 6: Perfil de 12 propriedades leiteiras do interior de SP

Item

Genética

Criação de bezerras

IA, TE, FIV, Genotipagem

Nutrição

Adubação de pastagem

Análise de necessidades nutricionais

Análise de solo

Forrageiras adaptadas ao clima e região

Forrageiras específicas para a seca

Nutrição

iLPF

Irrigação de pastagem

Pastejo rotacionado

Silos de cobertura

\section{Sanidade}

Análise da água

Controle de mastite

Controle de moscas e carrapatos

INs 76 e 77/2018

Gestão, Manejo e Operação

Anotação de informações climáticas

Anotação de informações financeiras

Anotação de informações zootécnicas

Assistência técnica especializada

Associação e Cooperativa

Cerca elétrica

Certificação

Destinação de resíduos

Painéis solares

Tratores e implementos

Treinamentos, capacitações

Venda para indústria

Fonte: Elaborado pelo autor.
\% que aplica Número de o item DMU's

$\begin{array}{ll}50,00 & 6 \\ 50,00 & 6\end{array}$

$\begin{array}{ll}58,00 & 7 \\ 41,00 & 5 \\ 67,00 & 8 \\ 50,00 & 6 \\ 66,00 & 8\end{array}$

$8,00 \quad 1$

25,00

$75,00 \quad 9$

$66,00 \quad 8$

9

8

$33,00 \quad 4$

$\begin{array}{cc}100,00 & 12 \\ 91,00 & 11 \\ 75,00 & 9\end{array}$

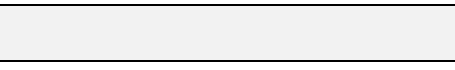

\begin{tabular}{cc}
67,00 & 8 \\
91,00 & 11 \\
\hline 100,00 & 12 \\
\hline 67,00 & 8 \\
58,00 & 7 \\
\hline 75,00 & 9 \\
\hline 8,00 & 1 \\
58,00 & 7 \\
\hline 8,00 & 1 \\
75,00 & 9 \\
\hline 67,00 & 8 \\
\hline 75,00 & 9
\end{tabular}

Com relação ao item Genética, em ambas as questões o percentual é de 50\% de aplicação, número baixo, visto que a questão genética interfere diretamente na produção do animal. 
No que diz respeito à nutrição, das 9 questões, 6 resultam em percentuais entre 50 e 75\%. Os números apresentam possibilidades de melhoria significativa. Especialistas defendem que a produção de leite, advém, em sua maior parte, do que os animais se alimentam. Desta forma, promover uma alimentação qualificada para o rebanho resultará em resultados ótimos na produção leiteira. A integração lavoura, pecuária e floresta como sistema tecnológico é aplicada em apenas 1 DMU, número baixo, e que, no caso de utilização adequada e de forma planejada, propicia sobremaneira maior produtividade, redução de custos, maior lucratividade e bem-estar aos animais.

Em $100 \%$ das propriedades realiza-se o controle da mastite, que diferente de Melo e Teixeira (2017), que observaram apenas 53,3\% de 17 propriedades da Zona da Mata Mineira realizavam o controle de mastite; além disso, $91 \%$ faz o controle de moscas.

Apenas quatro propriedades analisadas (33\%) fizeram a análise da água para a dessedentação do rebanho, número expressivo negativamente, pois este pode ser um fato gerador de doenças nos animais.

O item Gestão, Manejo e Operação demonstra anotações das informações zootécnicas e financeiras com percentuais de $91 \%$ e $100 \%$ respectivamente como sendo mais expressivos. Entretanto, além de colher dados, é preciso interpretar as informações para a tomada de decisões mais assertivas para o negócio. Oito propriedades (67\%) contam com assistência técnica especializada, o que torna um diferencial importante.

A escrituração zootécnica e financeira é realizada em todas as DMU's eficientes. Embora haja dedicação para esta tarefa, identificou-se que há precariedade na interpretação destas informações como também inutilização para a elaboração de planejamento, especialmente na construção de cenários em produtividade, faturamento, custos operacionais e indicadores de resultado. Tais fatores influenciam diretamente nos resultados. De acordo com Sampaio (2013), a coleta e processamento de informações para avaliar os resultados é essencial e possibilita potencializar o negócio rural.

A assistência técnica especializada é realizada em $75 \%$ das propriedades eficientes. Gonçalves et al. (2008) relataram que a maioria das propriedades leiteiras avaliadas apresenta problemas de ineficiência e que melhorias podem ser alcançadas com apoio técnico, crédito rural e capacitação. O nível ótimo de eficiência é atingido na combinação dos diversos recursos envolvidos (Stokes, 2007).

Duas das quatro propriedades eficientes participam de associação e ou cooperativa de produtores de leite. Segundo Buss et al. (2020), fatores como capacitação e assistência técnica são imprescindíveis para a atividade leiteira. 
De forma geral, identificou-se com o estudo, que o produtor de leite toma suas decisões de forma intuitiva. Este tipo de abordagem é denominado decisão operacional, que se caracteriza de ciclos curtos, baixos recursos e tem foco na melhoria (Matheson \& Matheson, 1998; Dacorso, 2000).

\section{Considerações Finais}

O produtor de leite é comprometido pela profissão e tem como objetivo obter retorno financeiro na sua atividade, mas muitas vezes não analisa adequadamente seus resultados produtivos. O acompanhamento dos números para análise de desempenho e tomada de decisão, visando reduzir riscos, mostrou-se essencial para o sucesso ou o fracasso da atividade leiteira.

Como limitação do estudo, observa-se a ausência, junto ao produtor leiteiro, de um planejamento estratégico de curto, médio e longo prazo, com informações claras, objetivas e medições constantes, não somente para correção de objetivos e metas, caso seja necessário, mas para melhor avaliação dos dados e informações relacionados à eficiência. Poucos produtores do grupo estudado utilizam indicadores de resultado nas áreas agronômica, veterinária, zootécnica e financeira. Existem, na atualidade, inúmeros sistemas que oferecem tais informações de forma rápida para apoio nas decisões. As ações de desenvolvimento e capacitação em parceria com entidades públicas e privadas devem ser contínuas, pois há estímulo para a introdução de tecnologias, inovações e boas práticas de produção e gestão. A formação de grupos para comprar e vender contribui para a redução dos gastos operacionais e melhoria da receita.

A aproximação junto a entidades envolvidas na cadeia produtiva também promove e dissemina boas práticas de produção, técnicas, inovações que consequentemente incrementa sua renda.

Apenas um em cada três produtores de leite são considerados eficientes, porque promovem melhorias incrementais e estruturais. É um número muito baixo pela posição que o Brasil ocupa no agronegócio mundial. Esses resultados podem levar mais produtores a abandonar a atividade nos próximos anos; portanto, todos devem se unir para implementar novas soluções.

\section{Referências}

ALI, A. I., SEIFORD, L. M. (1993). The Mathematical Programming Approach to Efficiency Analysis. In: FRIED, H. O., LOVELL, C. A. K., SCHIMIDT, S. S. (Orgs.). The Measurement of Productive Efficiency: Techniques and Application. New York: Oxford University Press, Cap. 3, p. 120-159. 
Arzubi, A.; Berbel, J. (2002). Determinación de Índices de Eficiencia mediante DEA en explotaciones lecheras de Buenos Aires. Investigación Agraria. Producción y Sanidad Animal, v. 17 , n. 1-2, p. 103- 23.

ABIA - Associação Brasileira Da Indústria Dos Alimentos. (2019). Dados estatísticos. Disponível em:<https://www.abia.org.br/vsn/tmp_2.aspx?id=393>. Acesso em: 16 dez. 2019.

Azambuja, A. M. V. (2002). Análise de Eficiência na Gestão do Transporte Urbano por Ônibus em Municípios Brasileiros. 385f. Tese (Doutorado em Engenharia de Produção) - Programa de Pós-Graduação em Engenharia de Produção, Universidade Federal de Santa Catarina, Florianópolis/SC.

Barbieri, R. S; Oliveira, L. B. G; Sabbag, O. J. (2016). Análise de eficiência de produtores de leite em assentamento rural. Espacios, Vol. 37, nº 10, p. 22.

Batalha, M. O. (2012). Gestão Agroindustrial. São Paulo, $3^{\mathrm{a}}$ ed. Atlas, 440p.

Brandão, A. S. P. (2001). Aspectos econômicos e institucionais da produção de leite no Brasil. In: Vilela, D.; Bressan, M.; Cunha, A. S. Cadeia de lácteos no Brasil: restrições ao seu desenvolvimento. Juiz de Fora: Embrapa Gado de leite, p. 39-72.

Buss; R. E. Sabbag; O. J. Mendieta; F. H. P. (2020). Eficiência da produção leiteira na microrregião de Dourados/MS: Aplicação da Análise Envoltória de Dados. Exacta: Engenharia de Produção. São Paulo, p. 649-667. https://doi.org/ 10.5585/exactaep.v18n3.12360.

Caiazza, R. Volpe, T.; Stanton, J. L. (2016). Innovation in Agro-Foods: A Comparative Analysis of Value Chains. Journal of International Food \& Agribusiness Marketing. v. 28, n. 3, p. 240-253. https://doi.org/10.1080/08974438.2015.1068722.

Canziani, J. R. (2003). Cadeias agroindustriais: o programa empreendedor rural. Curitiba: SENAR-PR, 24p.

Cardenas, L. Q.; Pacheco, D.; Dias, L. F. (2018). The agribusiness innovation in bovine supply chain in Brazil: landscape and challenges. Brazilian Review of Economics \& Agribusiness, v. 16, n. 3, p. 305-326. https://doi.org/10.25070/rea.v16i3.7879.

Charnes; A. Cooper; W. W. Lewin; A. Y. Seiford; L. M. (1997). Data Envelopment Analysis: theory, methodology and application. Massachusetts, EUA. 
Coelli, T. J. (1996). A guide for DEAP version 2.1: a data envelopment analysis program. Armidale, Austrália: University of New England, 49 p. (CEPA Working Papers, 08/96).

Corrêa, C. C.; Veloso, A. F.; Barczsz, S. S. (2010). Dificuldades enfrentadas pelos produtores de leite: um estudo de caso realizado em um município de Mato Grosso do Sul. In: Congresso Brasileiro De Sociologia, 2010, Campo Grande. Anais. Campo Grande.

Dacorso, A. L. R. (2000). Tomada de decisão e risco: a administração da inovação em pequenas indústrias químicas. 254f. Dissertação de mestrado. Departamento de Administração da Universidade de São Paulo.

Dantas, V. V., Oaigen, R. P., Santos, M. A. S., Marques, C. S. S., Silva, F. (2016). Typology of dairy production systems in the Eastern Amazon, Pará, Brazil. Livestock Research for Rural Development. v. 28, n. 6, 12p.

Dias, J. C. (2012). As raízes leiteiras do Brasil. 11 a ed. São Paulo: Barleus, 167 p.

Embrapa. (2018) Anuário Leite 2018: Indicadores, tendências e oportunidades para quem vive no setor leiteiro. Juiz de Fora. Disponível em: https://www.embrapa.br/busca-de-publicacoes//publicacao/1094149/anuario-leite-2018-indicadores-tendencias-e-oportunidades-para-quemvive-no-setor-leiteiro. Acessado em: 21 jan. 2020.

Embrapa. (2019). Anuário Leite 2019: novos produtos e novas estratégias da cadeia do leite para ganhar competitividade e conquistar os clientes finais. Juiz de Fora. Disponível em: https://www.embrapa.br/busca-de-publicacoes/-/publicacao/1109959/anuario-leite-2019novos-produtos-e-novas-estrategias-da-cadeia-do-leite-para-ganhar-competitividade-econquistar-os-clientes-finais. Acessado em: 26 jul. 2020.

Eurich; J. Neto; P. H. W. Rocha; C. H. (2016). Pecuária leiteira em uma colônia de agricultores familiares no município de Palmeira, Revista Ceres, Viçosa, v. 63, n. 4, p. 454-460. https//doi.org/10.1590/0034-737X201663040004.

Farrel, M. J. (1957). The measurement of productive efficiency. Journal of the Royal Statistical Society, v. 120, n. 3, p. 253-290. https://doi.org/10.2307/2343100.

Ferenhof, H. A., Bonamigo, A., Cunha, A., Forcellini, F. (2019). Relationship between barriers and key factors of dairy production in Santa Catarina, Brazil. British Food Journal, v. 121, n. 2, p. 304-319. https://doi.org/10.1108/BFJ-07-2018-0424. 
Food and Agriculture Organization of The United Nations - FAO. (2016). Milk and dairy products in human nutrition. Roma. Disponível em: <http://www.fao.org/docrep/018/i3396e/i3396e.pdf >. Acessado em: 15 dez. 2019.

García-Villegas, J., García-Martínez, A., Arriaga-Jordán, C., Ruiz-Torres, M., Rayas-Amor, A., Dorward, P., \& Martínez-García, C. (2020). Use of information and communication technologies in small-scale dairy production systems in central Mexico. Experimental Agriculture, 56(5), 767-779. doi:10.1017/S0014479720000319.

Gonçalves, R. M. L.; Vieira, W. C.; Lima, J. E.; Gomes, S. T. (2008). Analysis of technical efficiency of milk-producing farms in Minas Gerais. Economia Aplicada, São Paulo, y. 12, n. 2, p. 321-335. https://doi.org/10.1590/S1413-80502008000200007.

Ibge. (2019). Produção Pecuária Municipal. Rio de Janeiro, vol. 46, p. 1-8. Disponível em:<https://biblioteca.ibge.gov.br/visualizacao/periodicos/84/ppm_2018_v46_br_informativo .pdf">. Acessado em: 05 dez. 2019.

Kassai, S. (2002). Utilização da Análise por Envoltória de Dados (DEA) na Análise de Demonstrações Contábeis. Tese (Doutorado). Departamento de Contabilidade e Atuária. Faculdade de Economia, Administração e Contabilidade. Universidade de São Paulo, São Paulo.

Klerkx, L., \& Begemann, S. (2020). Supporting food systems transformation: The what, why, who, where and how of mission-oriented agricultural innovation systems. Agricultural Systems, $184,102901$.

Lima, V. A. M. O. Souza, C. C. Neto, J. F. Dos Reis. Lins, R. S. Frainer, D. M. (2016). Análise da eficiência de pequenas propriedades rurais através do método da Análise Envoltória de Dados. Informe GEPEC, vol. 20, n. 2, p. 58-70.

Manual de Oslo (2018). Guidelines for Collecting, Reporting and Using Data on Innovation. Paris/Eurostat, Luxembourg. OECD Publishing. 4ª ed. E-book, 254 p. Disponível em: https://doi.org/10.1787/9789264304604-en. Acesso em: 07 dez. 2018.

Miranda, A. J. R., \& Graciosa, M. G. (2018). Influência do volume total de leite produzido na eficiência produtiva e reprodutiva em grandes e pequenas propriedades do municipio de Valença-RJ. Revista Saber Digital, 11(1), 85-94. 
Matheson, D.; Matheson, J. (1998). The smart organization: creating value through strategic R \& D. Boston, HBS.

Mello, J. C. C. B. S.; Meza, L. A.; Gomes, E. G.; Miondi Neto, L. (2005). Curso de Análise Envoltória de Dados. In: XXXVIII Simpósio Brasileiro de Pesquisa Operacional. Anais.... Gramado (RS).

Melo, I. L. C.; Teixeira, R. M. A. (2017). Perfil das propriedades leiteiras pertencentes ao programa curral bonito do município de rio Pomba, MG. Revista do Instituto de Laticínios Cândido Tostes, Juiz de Fora, v. 72, n. 1, p. 19-30. https://doi.org/10.14295/22386416.v72i1.551.

Nascimento, A. C. C. Lima, J. E. Braga, M. J. Nascimento, M. Gomes, A. P. (2012). Eficiência técnica da atividade leiteira em Minas Gerais: uma aplicação de regressão quantílica. Revista Brasileira de Zootecnia, v. 41, $\mathrm{n}^{\circ}$ 3, p. 783-789. https://doi.org/10.1590/S151635982012000300043.

Pachiel, M. G. (2009). Eficiência produtiva de usinas de cana de açúcar do estado de São Paulo. Dissertação (Mestrado em Economia). Universidade Federal de Viçosa, Viçosa/MG.

Pereira, N. A. (2014). Avaliação da eficiência das principais regiões produtoras de cana de açúcar por meio da Análise Envoltória de Dados (DEA). Dissertação de Mestrado (Ciências Contábeis). Universidade Federal de Uberlândia/MG.

Sabbag, O. J. Costa, S. M. A. L. Barroso, R. M. (2017). Condicionantes da eficiência técnica da piscicultura na região noroeste paulista. In: $55^{\circ}$ Congresso da Sociedade Brasileira de Economia, Administração e Sociologia Rural. Santa Maria, RS.

Sampaio, A. L. M. (2013). Análise do Processo Decisório na Atividade Rural: estudo de caso na Sojicultura. Dissertação (Mestrado). Universidade Federal da Grande Dourados - Faculdade de Administração, Ciências Contábeis e Economia, Dourados/MS.

Schreiber, C. (2002). Sources of innovation in dairy production in Kenya. International Service for National Agricultural Research. Disponível em: <https://cgspace.cgiar.org/bitstream/handle/10568/1848/Schreiber-2002innovation\%20in\%20dairy.pdf;sequence=1>. Acesso em 17 mar. 2019. 
Souza Almeida, F. M., Gomes, A. P., \& de Freitas, A. F. (2021). Social networks and efficiency in dairy farming: The case of the Program for the Development of Dairy Farming in Minas Gerais, Brazil. Livestock Science, 244, 104401.

Stokes, J. R. Tozer, P. R. Hyde, J. (2007). Identifying Efficient Dairy Producers Using Data Envelopment Analysis. Departament of Agricultural Economics and Rural Sociology. The Pennsylvania State University. American America Dairy Association. https://doi.org/10.3168/jds.2006-596.

Wilkinson, J. (2015). O Estado, a agricultura e a pequena produção. Centro Edelstein de Pesquisas Sociais, Rio de Janeiro, 229 p. E-book. 